\title{
DESERTIFICAÇÃO, MUDANÇAS CLIMÁTICAS E SECAS NO SEMIÁRIDO BRASILEIRO: UMMA REVISÃO BIBLIOGRÁFICA
}

\author{
Válter Cardoso Tavares ${ }^{1}$ \\ Ítalo Rodrigo Paulino de Arruda² \\ Danielle Gomes da Silva ${ }^{3}$
}

Resumo: O presente artigo trata-se de uma revisão bibliográfica e aborda a interrelação existente entre a desertificação, as mudanças climáticas e as secas no Semiárido brasileiro. A desertificação se apresenta como um dos maiores problemas ambientais em escala mundial e, em específico, na região do Semiárido brasileiro. Não obstante, grande parte dessa região já se encontra em um processo cada vez mais crescente de degradação das terras, atrelando-se a este fato a realidade das secas na região que, concatenada a desertificação, torna o Semiárido brasileiro ainda mais suscetível a este fenômeno. Destarte, o presente artigo buscou fazer uma discussão acerca da temática em questão e apresenta os desdobramentos da desertificação, das mudanças climáticas e das secas no Semiárido do Brasil, que juntos contribuem com a acentuação da fragilização socioeconômica e ambiental da região.

Palavras-chave: Degradação das terras. Clima. Semiaridez. Problemas socioeconômicos e ambientais.

\section{DESERTIFICATION, CLIMATE CHAMGES AND DROUGHTS IN THE BRAZILIAN SEMI-ARID: A BIBLIOGRAPHICAL REVIEW}

Abstract: The present article it is a bibliographical review and approaches the interrelation between desertification, climate change and droughts in the Brazil's Semi-arid region. The Desertification presents itself as one of the greatest environmental problems on a world scale and, specifically, in the Brazil's Semi-arid region. However, a large part of this region is already in an increasingly increasing process of land degradation, and this fact is linked to the reality of droughts in the region, which, together with desertification, makes the Brazil's Semi-arid region even more susceptible to this phenomenon. The purpose of this article is to present a discussion about the issue in question and presents the results of desertification, climatic changes and droughts in the Brazil' Semi-arid region, which together contribute to the accentuation of the region's socioeconomic and environmental fragilization.

Keywords: Degradation of the lands. Climate. Semiaridity. Socioeconomic and environmental problems.

\footnotetext{
1Universidade Federal de Pernambuco, Departamento de valtercardoso3@hotmail.com, https://orcid.org/0000-0002-0170-0637

2Universidade Federal de Pernambuco, Departamento de italotavares0811@gmail.com, https://orcid.org/0000-0003-2621-5993

3Universidade Federal de Pernambuco, Departamento de dannyavlis@yahoo.com.br, https://orcid.org/0000-0002-9391-1211
}

Geografia, Recife, Brasil, Geografia, Recife, Brasil, Geografia, Recife, Brasil, 


\section{DESERTIFICACIÓN, CAMBIOS CLIMÁTICOS Y SEQUÍAS EN EL SEMIÁRIDO BRASILEÑO: UNA REVISIÓN BIBLIOGRÁFICA}

Resumen: El presente artículo se trata de una revisión bibliográfica y aborda la interrelación existente entre la desertificación, los cambios climáticos y las sequías en el Semiárido brasileño. La desertificación se presenta como uno de los mayores problemas ambientales a escala mundial y, en específico, en la región del Semiárido brasileño. Sin embargo, gran parte de esa región ya se encuentra en un proceso cada vez más creiente de degradación de las tierras, atando a este hecho la realidad de las sequías en la región que, concatenada la desertificación, hace que el Semiárido brasileño aún más susceptible a este fenómeno. De este modo, el presente artículo buscó hacer una discusión a cerca de la temática en cuestión y presenta los desdoblamientos de la desertificación, de los cambios climáticos y de las sequías en el Semiárido de brasileño, que juntos contribuyen con la acentuación de la fragilización socioeconómica y ambiental de la región.

Palabras clave: Degradación de las tierras. Clima. Semiaridez. Problemas socioeconómicos y ambientales.

\section{Introdução}

$\mathrm{Na}$ atualidade os dados atinentes à desertificação mostram a gravidade do problema, uma vez que, entre outras características, afeta mais de um bilhão de pessoas no mundo e mais de 250 milhões de pessoas estão direta ou indiretamente afetadas pelo fenômeno da desertificação. As Nações Unidas estimam que a desertificação custa 42 bilhões de dólares por ano, ao passo que a prevenção representa um custo de apenas US\$ 10-20 bilhões por ano.Entre cinco e seis milhões de hectares de terra arável e produtiva perde-se todos os anos em razão da desertificação e declínio da produtividade (ROXO, 2006, apud TAVARES \& RAMOS, 2016).As causas da desertificação no mundo incluem o sobrepastoreio intensivo, o desmatamento, a gestão inadequada da agricultura, o consumo de lenha como combustível, a indústria e urbanização (MILLENNIUM ECOSYSTEM ASSESSMENT - MA, 2005).

Ainda segundo a MA (2005), as mudanças climáticas estão intrinsecamente coadunadas com o fenômeno da desertificação. As mesmas, portanto, provocam o aumento e a redução na abundância de espécies e mudanças na estrutura da comunidade biótica e na diversidade biológica. Isso implica terminantemente na perda da biodiversidade (perda de nutrientes e umidade do solo, redução da conservação do mesmo e, consequentemente, redução na estrutura da diversidade biológica) que estão associados ao processo erosivo do solo. Todos esses fatores amalgamados convergem para a perda da fertilidade dos solos e, subsequentemente, para o fenômeno da desertificação. 
As mudanças climáticas podem, adversamente, afetar a biodiversidade e acelerar a desertificação devido à diminuição na evapotranspiração e, consequentemente, a diminuição das chuvas nas terras secas, entre outros fatores correlatos.

As secas e a desertificação são dois fenômenos díspares em seus efeitos, no tempo/ espaço e nas suas causas. A "seca é um fenômeno natural reversível, de ocorrência esporádica ou repetida numa periodicidade complexa e não esclarecida" (SAMPAIO et al., 2003, p. 22). Os autores, ademais, argumentam que alguns efeitos da seca, como eliminação de algumas espécies, o abandono de culturas mais sensíveis e as consequências socioeconômicas da população, caso perdurem além do período da seca, podem ser enquadradas como parte do processo da desertificação, sendo as secas um agravante a mais. As áreas suscetíveis ao fenômeno da desertificação são mais vulneráveis aos efeitos das secas e, por isso, há uma estreita inter-relação entre os dois fenômenos.

A seca no Semiárido brasileiro não ocorre de forma homogênea, podendo haver anos de seca total, com efeitos observados em todas as áreas da região e secas parciais, onde apenas algumas áreas são atingidas. Todavia, as secas contribuem para o agravamento do fenômeno da desertificação no Semiárido brasileiro, além da predisposição ao fenômeno em pauta que é atribuída a esta região.

Recorrendo a literatura o presente artigo examina a inter-relação existente entre a desertificação, as mudanças climáticas e as secas no Semiárido brasileiro.

\section{A Desertificação: Um Resgate Histórico}

Para Macedo (2007) a desertificação remonta ao princípio dos anos de 1930, onde ocorreu, no Oeste dos Estados Unidos, uma grande tempestade de poeira que ficou conhecida mundialmente como "Dust Bowl". Este evento abrangeu uma área de cerca de $180.000 \mathrm{Km}^{2}$ e o mesmo acometeu os estados do Novo México, Kansas, Oklaroma e o Colorado.

Em relação a este evento, John Steinbeck em seu livro intitulado "The Grapes of Wrath", retrata o Dust Bowl da seguinte forma:

Nas estradas, onde o gado transitava e onde as rodas dos carros moíam o chão e as patas dos cavalos calcavam a terra, rompiam-se a crosta de lama e formavam-se a poeira. Tudo o que se movia lançava poeira no ar; um viajante levantava uma camada de poeira que lhe chegava até a cintura; uma carroça a fazia subir até aos taipais e um automóvel deixava uma nuvem de poeira atrás de si. 
Portanto, só muito tempo depois a poeira se assentava (STEINBECK, 1939, p. 3, tradução nossa).

No tocante a terminologia desertificação, foi o pesquisador francês André Aubreville que utilizou, pela primeira vez, o termo em 1949, em seu livro intitulado Climats, Forêts et Desertification de l'Afrique Tropicale. O mesmo caracterizou as áreas em vias de degradação na África Tropical com base na utilização inadequada dos recursos naturais disponíveis, a sabero corte indiscriminado de árvores e a prática das queimadas. A antropização exorbitante estava tornando as áreas relativamente semelhantes a desertos. Em sua obra o autor supracitado sinalizou dois efeitos que caracterizam o fenômeno da desertificação, quais sejama erosão dos solos devido ao processo laminar e/ ou pelo ravinamento concatenados ao desmatamento e o agravamento do déficit hídrico dos solos, pari passu, oriundos de uma maior exposição destes a radiação solar e a ação dos ventos secos (AUBREVILLE, 1949). Segundo Conti (1995, apud TAVARES, 2014, p. 23):

A preocupação de Aubreville em relação à problemática da expansão dos desertos, sobretudo nas bordas dos grandes desertos do mundo, como o Sahel nas bordas do Saara (África) e nas regiões de climas semiárido e subúmido, ganhou novos signatários ao longo de toda segunda metade do século XX. Estes estudiosos buscaram desenvolver alternativas no sentido de combater os efeitos do processo de expansão dos desertos nas regiões estudadas. Nessa direção, havia toda uma preocupação em desvencilhar desertificação de deserto e estabelecer um conceito específico para o mesmo. Nesse sentido, um fator determinante para o estabelecimento do conceito de desertificação reside no fato de que este fenômeno é dinâmico e está associado a períodos de longas estiagens, na ordem de décadas.

Os estudos de Aubreville, a princípio, não tiveram êxito, visto que o mundo estava saindo da Segunda Guerra Mundial e as prioridades estavam direcionadas para a reconstrução dos países. Os problemas de âmbito ambiental foram relegados em segundo plano (SZILAGYI, 2007). No entanto, as discussões a cercados problemas ambientais e, sobretudo, a desertificação, só retomaram após uma grande seca durante os anos de 1968 a 1973 que assolou a região do Sahel africano, ceifando centenas de milhares de seres humanos. Dessa forma,

Durante aqueles anos marcados pela seca, muitos seres humanos, principalmente crianças, perderam suas vidas nas mais miseráveis condições de higiene e alimentação, enquanto se assistia ao desenvolvimento das sociedades de consumo americana e europeia, baseada na propriedade e no bem-estar individual em detrimento de condições de vida socialmente igualitárias (MENDONÇA, 2004, p. 43, apud TAVARES, 2014, p. 23). 
De acordo com o MA (2005) as secas no Sahel reduziram a produtividade, deixando rala a cobertura vegetal e aumentando o albedo, reduzindo assim a ciclagem hídrica e a circulação da monção e, desta forma, implicando no decréscimo da precipitação.

Ainda de acordo com o MA (2005), a redução da cobertura vegetal pode também ser atribuída às atividades humanas, como por exemplo, as práticas insustentáveis do uso das terras (sobrepastoreio, aragem intensa, monocultura, entre outras). Essas práticas, particularmente em relação às secas ou aumento da densidade populacional na região do Sahel, contribuíram para a degradação do solo, o aumento da erosão hídrica e os elevados níveis de poeira suspensas no ar. Isso leva a acreditar que a combinação de fatores humanos e naturais pode acarretar perdas severas de produtividade e, consequentemente, fome para grandes contingentes populacionais.

Este acontecimento ocorrido na África impulsionou as Nações Unidas a realizar algumas conferências e assembleias nos anos de 1972 e 1974, objetivando discutir os problemas ecológico-sociais, bem como de preparar documentos e relatórios de efeitos práticos a serem analisados e votados na $1^{\underline{a}}$ Conferência das Nações Unidas de Combate à Desertificação - UNCOD (UNITED NATIONS CONFERENCE ON DESERTIFICATION), que ocorreu em Nairóbi - Quênia, na África, em 1977. Destarte, nas discussões de Nairóbi, a UNCOD classificou a desertificação como sendo:

[...] a diminuição ou a destruição do potencial biológico das terras, podendo conduzir definitivamente para condições desérticas. A degradação, em grande extensão, do ecossistema pode implicar a redução e a destruição do potencial biológico, o que trará prejuízos para a produção de plantas e de animais para diversos fins, quando a produtividade é necessária para fornecer suporte ao crescimento das populações (UNEP, 1978, p.79, apud TAVARES, 2014, p. 25).

De acordo com as definições oficiais da Conferência de Nairóbi, a desertificação corresponde: “a degradação das terras em áreas áridas, semiáridas e subúmidas secas resultante de vários fatores, incluindo variações climáticas e atividades humanas" (UNCCD, 2006, p. 209, apud TAVARES, 2014, p. 25). Portanto, as terras secas (incluindo as três categorias supramencionadas) de acordo com o MA (2005) compreende uma área de 41,3\% da superfície terrestre do planeta, onde vive $34,7 \%$ da população mundial referente aos dados do ano de 2000.

O termo "desertificação" passou a ser utilizado oficialmente no mundo inteiro e de forma muito recorrente, tanto nos meios acadêmicos quanto em outras 
instâncias, a partir da $1^{\underline{a}}$ Conferência das Nações Unidas de Combate à Desertificação. Portanto, alguns encontros e conferências ocorreram após esta Conferência, no sentido de consolidar a terminologia em questão.

O Brasil, portanto, realizou o maior encontro das Nações Unidas sobre Meio Ambiente, promovido pela UNCED (United Nations Conference on Environment and Development), a Rio-92 ou ECO-92 como é também conhecida. Este Encontro precedeu os demais e foi realizado na cidade do Rio de Janeiro em 1992. O mesmo contou com mais de 100 chefes de Estado e um dos documentos fruto desse evento é conhecido como a Agenda 21, a qual dedica o capítulo 12 de forma exclusiva ao combate à desertificação. Por último, interessa salientar que em 2004 o país elaborou o Programa de Ação Nacional de Combate à Desertificação e Mitigação dos Efeitos da Seca, o PAN-BRASIL.

Um dos pioneiros no estudo da desertificação no Brasil, portanto, foi o ecólogo João Vasconcelos Sobrinho. O mesmo selecionou seis áreas conhecidas como "Áreas Piloto", onde existem processos de degradação do solo e da cobertura vegetal. As seis áreas correspondem a Caatinga e ao Cerrado no Piauí, Inhamuns no Ceará, Seridó no Rio Grande do Norte, Cariris Velhos na Paraíba, Sertão Central em Pernambuco e o Sertão do São Francisco na Bahia (MMA, 2007). "Sua trajetória começou em 1971, quando da publicação da sua obra intitulado de "Núcleos de Desertificação nos Polígonos das Secas", onde Vasconcelos Sobrinho apresentou as primeiras ideias sobre os Núcleos de Desertificação" (MARIN, 2012, p. 92).

É importante elucidar que no mapeamento Brasil de 1998, foram considerados apenas quatro núcleos de desertificação, quais sejam Gilbués (Piauí), Irauçuba (Ceará), Seridó (Rio Grande do Norte) e Cabrobó (Pernambuco). Por motivos não esclarecidos pelo Ministério do Meio Ambiente, dois núcleos ficaram de fora, a saber, Cariris Velhos e Sertão do São Francisco, recebendo assim menos atenção pelo ministério supracitado e outras instituições (RIBEIRO et al., 2003).

As causas da desertificação, observados nesses quatro núcleos, são variáveis, uma vez que a natureza dos solos e da geologia de cada região são distintos. O processo de ocupação e a utilização antrôpica das áreas onde se encontram os quatro núcleos também variam muito de um para outro, muito embora as atividades que neles predominam estejam quase totalmente relacionadas com a agropecuária.

As causas e consequências da desertificação estão intrinsecamente interrelacionadas por mecanismos de retroalimentação (SAMPAIO et al., 2003), sendo 
vários e complexos os fatores que determinam as causas da mesma. Esses fatores podem ser de ordem social, econômica, cultural e política.

De acordo com o MA (2005) de 10 a 20\% das terras secas do mundo (árida, semiárida, subúmida, hiperárida) ou 10 a 20 milhões de $\mathrm{Km}^{2}$ encontram-se degradadas. Estima-se que entre 5 a 6 milhões de hectares perdem-se por ano devido à agricultura, por meio da degradação induzida pelo ser humano (GTZ, 2005, apud MILLENNIUM ECOSYSTEM ASSESSMENT, 2005).

O sobrepastoreio (com 680 milhões de hectares), o desmatamento (com 580 milhões de hectares), a gestão inadequada da agricultura (com 550 milhões de hectares), o consumo de lenha como combustível (com 137 milhões de hectares) e a indústria e urbanização (com 19.5 milhões de hectares) representam as maiores causas provocadas pela desertificação em escala mundial(UNEP, 2003, apud MILLENNIUM ECOSYSTEM ASSESSMENT, 2005). Entretanto, calcula-se que os custos econômicos mundiais anuais com a desertificação superem os US $\$ 42$ bilhões de dólares, ao passo que para se combater a mesma despende-se apenas uma média de US\$ 10 a 20 bilhões por ano (MILLENNIUM ECOSYSTEM ASSESSMENT, 2005).

Para Mérega (2003) as causas da desertificação não podem ser consideradas de forma isoladas, mas devem ser entendidas levando-se em consideração três fatores: socioeconômico (que envolve todos os aspectos antrópicos), biológico (flora e fauna) e físico (clima e solo).

De acordo com Silva (1993) as principais causas que desencadeiam o fenômeno da desertificação consistem, fundamentalmente, em: a) pré-disposição geoecológica que está relacionada com a interação entre clima e solo e b) a ação antrópica, por meio de formas diversas de atividades humanas sobre o meio ambiente, tornando-o geoecologicamente frágil.

Todos esses fatores concatenados podem levar a aceleração do fenômeno da desertificação em diversas regiões do planeta. Ademais, outros fatores, como evapotranspiração, baixo índice pluviométrico, entre outros, também podem contribuir para o fenômeno da desertificação nas áreas áridas, semiáridas e subúmidas secas do orbe terrestre.

Para Vasconcelos Sobrinho (1976) em estudo realizado no Nordeste do Brasil, as causas da desertificação estão sempre relacionadas a duas categorias, quais sejam as naturais e aquelas induzidas pelo ser humano.

De todos os fatores mencionados acima pelos autores supracitados, importa 
destacar que "o fator decisivo, apesar de tudo, de todas essas inclemências, é ainda o homem" (SOBRINHO, 1976, p. 16, grifo nosso).

Como mostrado anteriormente, as causas da desertificação são sobremaneira amplas, estando ligadas, respectivamente, aos fatores naturais e antrópicos. Há uma unanimidade em afirmar que os fatores em questão contribuem para o fenômeno da desertificação em diversas partes do planeta. Portanto, o fenômeno em pauta é resultado de uma série de fatores combinados, já mencionado, e que podem levar algumas áreas a assemelhar-se a regiões desérticas.

$\mathrm{Na}$ atualidade, os dados conhecidos acerca das consequências da desertificação revelam a gravidade do problema. É estimado que a desertificação afeta um quarto da superfície terrestre, onde vive um quinto da população mundial (D'DORICO et al., 2013).

Em que pese ao Semiárido brasileiro a desertificação já uma realidade em grande parte dessa região, com $180.000 \mathrm{Km}^{2}$ desertificados e $650.000 \mathrm{Km}^{2}$ ameaçados (DUQUE, 2006, apud TAVARES \& RAMOS, 2014). A desertificação, no que diz respeito a questão da espacialidade, ocorre de duas maneiras, quais sejam: de forma difusa no território, apresentando níveis diferenciados de degradação e, de forma concentrada, em áreas de intensa degradação do solo. As áreas de maior intensificação do processo de desertificação são denominadas de "núcleos de desertificação", terminologia já utilizada pelo professor João Vasconcelos Sobrinho (ROXO, 2006).

De acordo com o PAN-BRASIL (2004), com base nas áreas suscetíveis à desertificação, as mesmas são classificadas em: Muito Grave, Grave e Moderada respectivamente. No Brasil as áreas de âmbito Muito Grave totalizam $98.595 \mathrm{Km}^{2}$, correspondendo a aproximadamente $10 \%$ da região Semiárida brasileira. No caso das classificações dos tipos Grave e Moderado, ocupam 81.870 e 393.897 quilômetros quadrados (ROXO, 2006).

\section{Desertificação e Mudanças Climáticas}

A desertificação está associada à perda de biodiversidade e, concomitantemente, contribui com as mudanças climáticas globais por meio da perda da capacidade de absorção de carbono pelas plantas. Estima-se que 300 milhões de toneladas de carbono são perdidos para a atmosfera pelas terras secas como resultado da desertificação, o que corresponde a cerca de $4 \%$ do total das emissões globais (MA, 2005). 
A concentração de dióxido de carbono $\left(\mathrm{CO}_{2}\right)$ na atmosfera pode ser alterada em decorrência de fatores naturais e / ou pela ação antrópica (IPCC, 2014). De acordo com o quinto Relatório do IPCC, a ação antrópica vem contribuindo substancialmente para a concentração de $\mathrm{CO}_{2}$ na atmosfera terrestre (IPCC, 2014).

$\mathrm{O}$ incremento da concentração de $\mathrm{CO}_{2}$ a partir da Revolução Industrial a as projeções ulteriores deste elemento estabelecem uma conjuntura favorável para o aumento da fotossíntese e, por conseguinte, da produtividade primária em comunidades vegetais, com potencial impacto positivo para o desenvolvimento de agrossistemas (WALTER, 2015). Segundo Taiz e Zeiger (2013), a taxa fotossintética da maioria das espécies vegetais pode apresentar um aumento de 30 a $60 \%$ em ambientes com concentrações de 600 a 700 ppm (partes por milhão) de $\mathrm{CO}_{2} \mathrm{em}$ relação à taxa de fotossíntese com 370 ppm de $\mathrm{CO}_{2}$.

Apesar da taxa de fotossíntese elevada em termos de concentração de $\mathrm{CO}_{2}$, entretanto, foi observado que este efeito não atua de forma constante ao longo do ciclo das culturas e, as mais das vezes, não resulta no aumento de produtividade, haja vista a aclimatação das plantas (processo pelo qual as plantas se ajustam a determinadas mudanças em seu habitat) diante da elevada concentração de $\mathrm{CO}_{2}$ que consiste numa gama de modificações no metabolismo vegetal em diferentes níveis de tessitura, desde molecular e bioquímica até anatômico e morfológico (ARENQUE, 2014).

A diversidade biológica, portanto, está relacionada à maioria dos serviços advindos dos ecossistemas das terras secas que, por sua vez, são adversamente afetados pela desertificação. A vegetação e sua diversidade biológica referente à estrutura física são de fundamental importância para a conservação do solo, regulação da infiltração de água, escoamento superficial e clima local (MA, 2005).

Ainda de acordo com o MA (2005), diferentes espécies de plantas produzem, físico e quimicamente, uma variedade de componentes biológicos que junto com a diversidade da comunidade de micro e macrocomponentes, contribui para a formação e ciclagem do solo. O conjunto de plantas sustenta a produção primária que, por sua vez, fornece alimento, fibras, entre outros, e várias espécies vegetais que absorvem o carbono e regula o clima global. A exploração excessiva da vegetação leva a perda da produção primária e, consequentemente, a redução da absorção de carbono. Essa ruptura dos serviços interligados juntamente com a biodiversidade de plantas fornecidas pelas terras secas constitui o principal desencadeador da desertificação em suas várias manifestações, incluindo a perda 
de habitats da biodiversidade.

Figura 1 - Desertificação, mudanças climáticas e perda da biodiversidade.

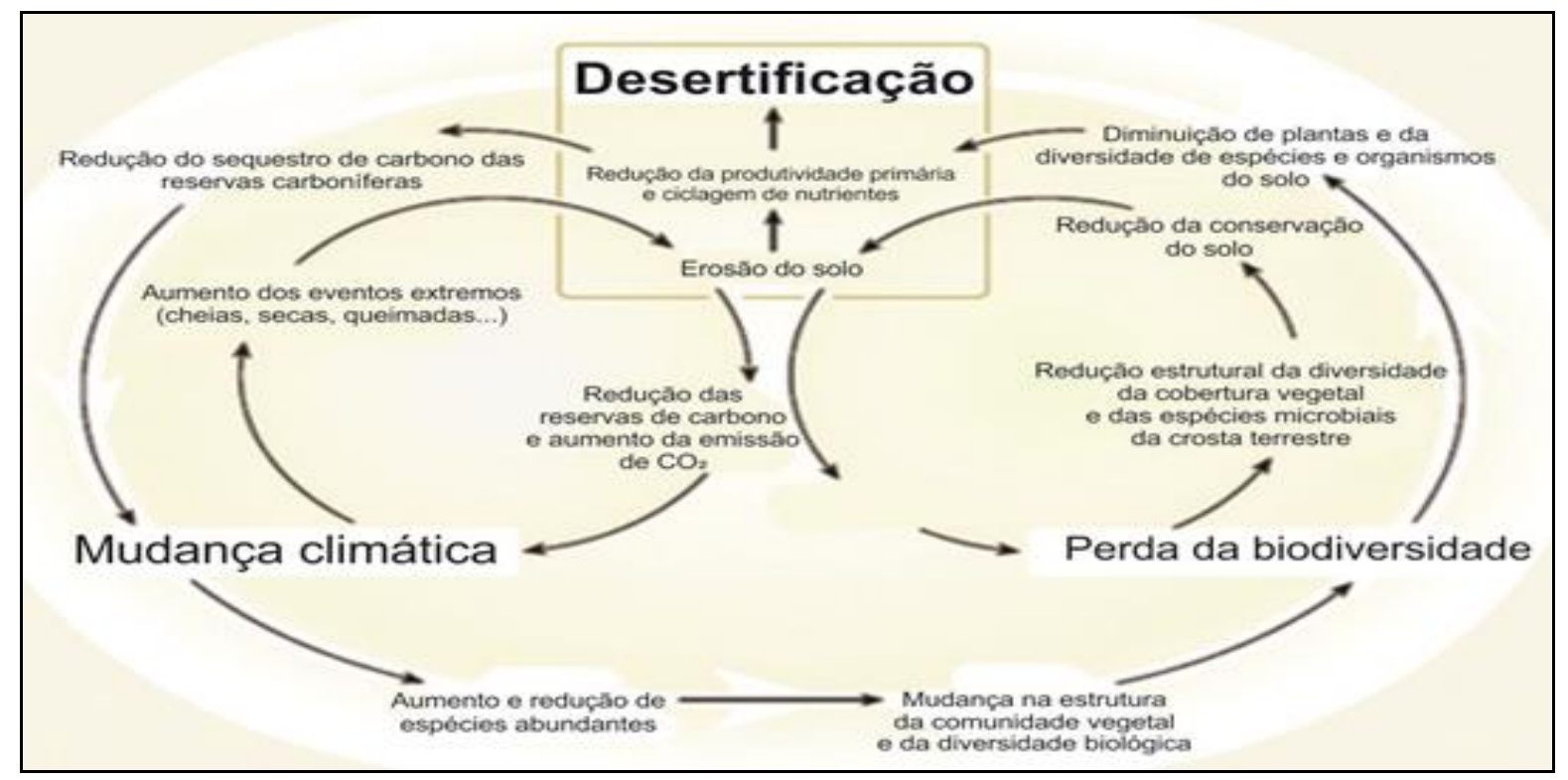

Fonte: MA (2005, apud TAVARES, 2014).

Conforme Figura 1, a desertificação afeta a mudança climática global por meio do solo e da perda da vegetação. O solo das terras secas contém mais de um quarto de todos os estoques de carbono orgânico do planeta, bem como aproximadamente todo o carbono inorgânico. Estima-se que 300 milhões de toneladas de carbono são perdidos para a atmosfera pelas terras secas como resultado da desertificação, o que corresponde a cerca de $4 \%$ do total das emissões globais (MA, 2005).

Ainda de acordo o MA (2005) as mudanças climáticas podem, adversamente, afetar a biodiversidade e acelerar a desertificação devido à diminuição na evapotranspiração e, consequentemente, a diminuição das chuvas nas terras secas. Como se pode observar na Figura1, há uma inter-relação entre desertificação, mudanças climáticas e perda da biodiversidade. Essa inter-relação se dá por meio da erosão do solo. Os principais componentes que provocam a perda da biodiversidade correspondem ao aumento e, concomitantemente, a redução de espécies abundantes, gerando um desequilíbrio e a mudança na estrutura da comunidade vegetal e da diversidade biológica.

Pode-se observar também, na Figura 1, os principais serviços impactados pela perda da biodiversidade. Desta forma, a diminuição das plantas e da diversidade das espécies dos organismos do solo e a redução da estrutura da biodiversidade da cobertura vegetal e a diversidade de espécies microbiais da crosta 
da terra, implicam diretamente na redução da conservação do solo, redução da produção primária e ciclagem de nutrientes que, por sua vez, estão relacionados com a redução do sequestro de carbono nas reservas carboníferas do solo.

Somado a isto, a erosão do solo que está relacionada com a redução da produção primária, ciclagem de nutrientes e a redução do sequestro de carbono nas reservas carboníferas do solo. Está última vai gerar mudanças climáticas, como a redução das reservas de carbono e aumento das emissões de $\mathrm{CO}_{2}$ na atmosfera. Esses fatores concatenados vão ocasionar o aumento de eventos extremos, como inundações, secas e queimadas que impactam significativamente as terras, causando processos erosivos (MA 2005).

Por último, as mudanças no clima provocam a redução na abundância de espécies e mudanças na estrutura da comunidade biótica e na diversidade biológica. Destarte, esses aspectos estão diretamente inter-relacionados com o fenômeno da desertificação como se pode observar na Figura 1. Como se pode perceber, a desertificação caracteriza-se como um dos maiores problemas socioeconômico e ambiental da humanidade. A mesma provoca uma miríade de danos às sociedades e ao meio ambiente.

\section{Desertificação e Mudanças Climáticas no Semiárido Brasileiro}

Geograficamente, o Semiárido brasileiro tem uma extensão de $969.589 \mathrm{Km}^{2}$ e abrange $70 \%$ do território do Nordeste e $63 \%$ de sua população. O mesmo é, portanto, constituído pelos Estados do Piauí, Ceará, Rio Grande do Norte, Paraíba, Pernambuco, Alagoas, Sergipe e Bahia, além do norte de Minas Gerais e oeste do Espírito Santo (MMA, 2010).

Segundo o Quarto Relatório de Avaliação do International Panel on Climate Change (IPCC, 2007), o Semiárido brasileiro poderá se tornar uma das regiões mais acometidas pelas mudanças climáticas e se tornar mais árido, podendo ocasionando um aumento na frequência e na intensidade das secas e, consequentemente, reduções na disponibilidade de recursos hídricos. Destarte, essas alterações no clima da região poderão resultar no impacto sobre a vegetação, a biodiversidade e sobre as atividades que dependem dos recursos naturais (MARENGO, 2008).

Segundo o último relatório do IPCC AR5 (2014), os sistemas naturais e humanos em todos os continentes e também os oceanos têm sofrido impactos. Estes revelam interações com sistemas produtivos, particularmente na agricultura, 
com ecossistemas e com as condições de vida da população, em especial, a mais pobre.

O relatório especial de extremos do IPCC, Managing the Risks of Extreme Events and Disasters to Advance Climate Change Adaptation - SREX sinaliza que o Nordeste terá maior frequência de períodos secos, mais intensos e longos, podendo virar secas sazonais (MARENGO, 2014). Ainda de acordo com o autor (op. cit., 2014), os relatórios do Painel Brasileiro de Mudanças Climáticas (PBMC) e do IPCC mencionam a influência antrópica sobre o sistema climático.

O Semiárido apresenta os maiores índices de vulnerabilidade sócioeconômica com grande parte da população desenvolvendo atividades agrícolas, como a agricultura de sequeiro, por exemplo, com baixo grau de tecnificação e elevada dependência da disponibilidade de recursos naturais. Dessa forma, os potenciais impactos negativos sobre os recursos hídricos e suas consequências na agricultura de sequeiro poderão comprometer a população da região (ANGELOTTI et al., 2011).

A produtividade agrícola, portanto, pode afetar diametralmente a segurança alimentar e a economia do país. Dessa forma, com base nos cenários futuros, há estimativas de declínio na produção agrícola, que irá influenciar no PIB do país (CERRI e CERRI, 2007). Segundo estudos realizados por Deconto (2008), não havendo adoção de medidas de mitigação dos efeitos das secas e das mudanças climáticas no Semiárido, poderão ocorrer alterações na lógica da produção agrícola do Brasil, com consequentes perdas na ordem de bilhões de reais.

Para Féres et al. (2009), as mudanças climáticas na Região Nordeste irão impactar, de forma negativa, a produtividade de culturas agrícolas tais como o milho, feijão, cana-de-açúcar, etc., ocasionando perdas sobremaneira expressivas, com exceção da mandioca e congêneres as quais são mais resistente a temperaturas mais elevadas.

De acordo com dados da Food and Agriculture Organization of the United Nations - FAO (2017) em que pese as transformações do clima, as mesmas poderão colocar milhões de pessoas em um ciclo vicioso de miséria e má nutrição. Ainda de acordo com os dados da FAO (2017) até 2050 quedas na produção agrícola coadunadas às mudanças climáticas poderão elevar em $20 \%$ o risco de fome no mundo.

O Semiárido brasileiro, portanto, é uma das regiões mais vulneráveis à variabilidade climática atual e às mudanças climáticas futuras no país. Não obstante 
o Semiárido ser dotado de níveis de precipitação relativamente elevados - de 400 $\mathrm{mm}$ a $800 \mathrm{~mm}$ por ano e, em algumas ocasiões, até $1.000 \mathrm{~mm}$ anuais - (MMA, 2010), as atividades agrícolas estão fortemente limitadas por padrões de precipitação insuficientes e pouco confiáveis, concentradas em poucos meses (três a quatro), bem como níveis de evapotranspiração elevados. Portanto, a falta de acesso a recursos hídricos e recorrentes eventos climáticos extremos, como as secas, têm afetado durante séculos as atividades agrícolas na região semiárida do país, causando, dentre outros fatores, má-nutrição, migração e mortes prematuras (OBERMAIER, 2011).

\section{Desertificação e as Secas no Semiárido Brasileiro}

A terminologia "seca" se refere a um período de tempo ao qual a escassez de chuvas produz um desequilíbrio hidrológico com impactos sociais, econômicos e ambientais. Durante muito tempo, a seca assumiu uma miríade de conceitos polêmicos e, muitas vezes, fora do campo científico. Porém, foi Thomaz Pompeu Sobrinho, um dos maiores estudiosos do fenômeno, quem esboçou uma definição mais coerente a respeito do assunto. Para ele

As secas, como ordinariamente entendemos, são fenômenos físicosociais. Oferecem uma face física e outra humana que se entrosam mais ou menos intimamente, produzindo efeito de ordem social, cuja morfologia é função de algumas variáveis independentes; destas, as mais importantes são a densidade demográfica da região assolada e o nível cultural das populações atingidas (POMPEU SOBRINHO, 1982, p. 19).

Ainda de acordo com o autor, quando da ocorrência de uma estiagem ${ }^{4}$ em uma determinada região desértica, esta não desencadeia nenhuma repercussão social, visto que é meramente um fenômeno de ordem físico-geográfico. Porém, se o mesmo fenômeno ocorrer numa região densamente povoada, como é o caso do Semiárido brasileiro, aquelas comunidades que tiverem um nível de adaptação mais elevado sofrerão menos com os efeitos da seca.

\footnotetext{
${ }^{4}$ Seca, no rigor léxico, significa estiagem, falta de umidade - da chuva provém a água necessária á vida na terra. O problema das secas, assim concebido, seria simplesmente o problema da água, isto é, do seu suprimento. Mas, a palavra seca, referida a uma porção de território habitado pelo homem, tem significado muito mais compreensiva. Com efeito, o fenômeno físico da escassez de chuva influi no homem pela alteração profunda que dela decorre para as condições econômicas da região que, por sua vez, se refletem na ordem social. Assim concebida a seca é um fenômeno muito vasto tanto de natureza física quanto econômica e social. O problema das secas é, portanto, um problema múltiplo. Verdadeiramente não há um problema, há problemas (LISBOA, 1984, p. 12).
} 
Importa mencionar que os mecanismos de enfrentamento ao problema das secas são muito mais concernentes as medidas paliativas adotadas pelos órgãos governamentais como, por exemplo, as alternativas políticas do DNOCS Departamento Nacional de Obras Contra as Secas, há tempos pretéritos, entre outras, de âmbito técnico e imediatista, do que com o desenvolvimento cultural e, sobretudo, educacional da comunidade envolvida.

A seca constitui um problema muito antigo, havendo relatos que indicam que os povos indígenas tiveram que enfrentar, constantemente, este problema. Em épocas de grandes estiagens, os mesmos migravam para o litoral em busca de alimentos para sua sobrevivência (SANTOS, 1994).

Levando-se em conta toda a bibliografia referente à seca no Nordeste Semiárido brasileiro, chega-se à conclusão de um total de 174 secas registradas, sem contar com as de 1990, 1993, 1997 e 1999 que foram descritas no início do século XXI (BOTELHO, 2002). No quadro abaixo, elaborado por Medeiros (2002), pode-se visualizar a ocorrência de secas, concebida pelo autor como um problema de âmbito físico e socioeconômico, no Nordeste de acordo com os respectivos séculos, como mostra o Quadro 1.

Quadro 1 - Ocorrência de secas no nordeste do Brasil.

\begin{tabular}{|c|c|}
\hline Séculos & Número de Ocorrência de Secas \\
\hline XVI & 8 \\
\hline XVII & 19 \\
\hline XVIII & 47 \\
\hline XIX & $\mathbf{5 7}$ \\
\hline XX & 43 \\
\hline Total & 174 \\
\hline
\end{tabular}

Fonte: Medeiros (2002, grifo nosso).

Interessa enfatizar, de acordo com o Quadro 1, que há um aumento significativo das secas de forma geométrica e crescente até o século XIX, onde há um grande número de ocorrências. A partir do século XX tem-se uma ligeira queda.

Segundo Carvalho (2012), no século XXI, de 2001 a 2010, houve no Nordeste brasileiro cinco secas que assolaram esta região tão suscetível à ocorrência deste evento. Acrescenta-se, nesse contexto, as secas de 2012 a 2016, contabilizando mais quatro anos consecutivos de secas e que já se configura como uma das maiores secas dos últimos trinta anos (MARTINS e MAGALHÃES, 2015). 
De acordo com Mendes (1986) existem dois tipos de secas no Semiárido brasileiro, quais sejam estacionais e periódicas. A primeira, que ocorre todos os anos, no segundo semestre e que se insere no regime hidrológico e climático da região, que se caracteriza muito mais como um período de estiagem e, a segunda que ocorre em intervalos de tempos, mas que causa grandes danos à agropecuária da região. O intervalo de tempo das secas periódicas varia sobremaneira, bem como sua duração. De acordo com a distribuição espacial e a intensidade, as secas são classificadas de três maneiras, a saber seca total, parcial (seca verde) e seca hidrológica.

A seca total ocorre quando há baixa precipitação e distribuição assimétrica das chuvas, tornando difícil a alimentação das populações e dos rebanhos e impossibilitando a manutenção dos reservatórios de água para o consumo humano e animal. A parcial (seca verde) ocorre quando há chuvas abundantes, porém mal distribuídas em termos de tempo e espaço. E por último, a hidrológica que se caracteriza por uma precipitação pequena, mas bem distribuída. As chuvas, nesse tipo de seca, são suficientes apenas para dar suporte à agricultura de autoconsumo e às pastagens (MENDES, 1986).

Já para Herrmann e Hutchinson (2006) há quatro tipos de secas de acordo com o aumento da severidade, quais sejam meteorológica, hidrológica, agrícola e socioeconômica. As secas meteorológicas são definidas apenas sobre as bases de precipitação fora da média; secas hidrológicas estão associadas aos efeitos das baixas precipitações sobre a superfície terrestre e o estoque de água subterrânea do que propriamente apenas as baixas precipitações, e ocorre antes das secas meteorológicas; as secas agrícolas têm como foco os impactos, especificamente, sobre as colheitas e está relacionada à redução do estoque de água para a agricultura; e, por último, as secas socioeconômicas que estão relacionadas aos impactos cumulativos de secas meteorológicas, hidrológicas e agrícolas sobre o funcionamento dos sistemas socioeconômicos, como por exemplo, a oferta e demanda de alguns bens e serviços econômicos (HERRMANN e HUTCHINSON, 2006).

Depreende-se que a seca não é tão somente um fenômeno atmosférico que atinge há anos o Nordeste Semiárido brasileiro, mas há também uma conotação social de grande relevância, onde um imenso contingente populacional de pessoas e animais residentes dessa região é acometido por este evento de âmbito natural. A 
Figura 2 detalha a incidência de secas na região do Semiárido brasileiro.

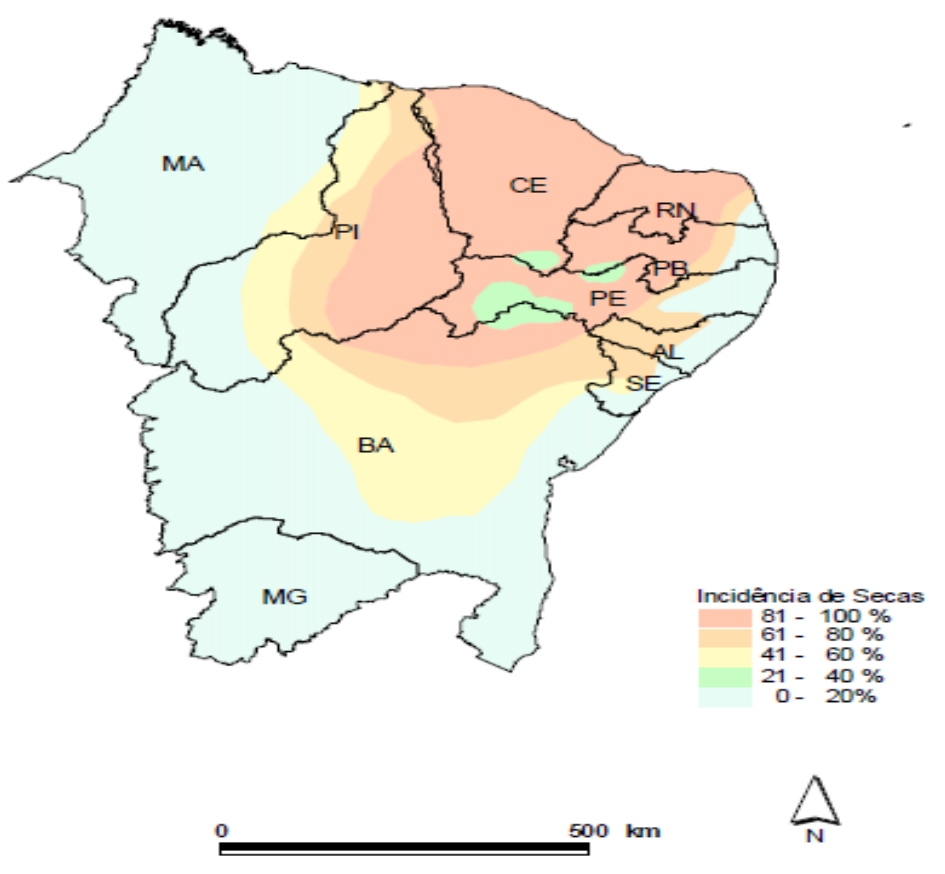

Fonte: Carvalho et al. (1973).

De acordo com o Pan-Brasil (2004) as áreas mais afetadas pelas secas são aquelas cuja ocorrência depende da ação da Zona de Convergência Intertropical (ZCIT). As mesmas apresentam uma determinada simetria física, onde os solos são relativamente mais pobres em relação às demais zonas geoeconômicas do Nordeste, quais sejam Zonas da Mata, do Agreste e dos Cerrados da Bahia. Nestas zonas supracitadas, a precipitação pluviométrica ocorre em torno de 400 a $800 \mathrm{~mm}$ de chuvas anuais. Entretanto, no interior das áreas afetadas pelas secas há um espaço, já denominado de "miolão semiárido", onde as secas ocorrem com frequência entre 81 e 100\%, conforme Figura 2. Nesse espaço, a variabilidade climática é extremamente acentuada.

Em que pese a inter-relação entre a seca e a desertificação, as mesmas são dois fenômenos diferentes em seus efeitos, no tempo/ espaço e nas suas causas. A "seca é um fenômeno natural reversível, de ocorrência esporádica ou repetida numa periodicidade complexa e não esclarecida" (SAMPAIO et al., 2003, p. 22). O autor, ademais argumenta que alguns efeitos da seca, como eliminação de algumas espécies, 0 abandono de culturas mais sensíveis $e$ as consequências socioeconômicas da população, caso perdurem além do período da seca, podem ser enquadradas como parte do processo da desertificação, sendo as secas um agravante a mais. As áreas suscetíveis à desertificação são mais vulneráveis aos 
efeitos da seca, por isso, há uma estreita inter-relação entre os dois fenômenos.

De acordo com Le Houérou (1996, p. 158) "há muita diferença entre seca e desertificação. A seca, sendo uma característica normal dos climas secos, é de uma natureza tipicamente temporal, deixando poucas consequências permanentes". Portanto, há efeitos só na produção e não na produtividade em longo prazo. Ainda de acordo com o autor, a desertificação é o oposto. Ela tem efeitos de longa duração, com consequências, muitas vezes, irreversíveis e permanentes sobre o potencial de produção (isto é, na possibilidade de o meio ambiente manter sua produtividade em longo prazo). Em síntese,

O Semiárido Nordestino, além da vocação geoecológica para a desertificação que possui, devido à ocorrência de secas e as características do clima e do solo, tem, na ação do homem, favorecida pela pressão demográfica, a responsável pelo alarde processo de desertificação que a região está sofrendo (MENDES, 1986, p. 112, grifo nosso).

A seca no Semiárido brasileiro não ocorre de forma homogênea, podendo haver anos de seca total, com efeitos observados em todas as áreas da região e, secas parciais, onde apenas algumas áreas são atingidas. Todavia, a seca contribui para o agravamento do fenômeno da desertificação no Semiárido brasileiro, além da predisposição ao fenômeno em pauta que é atribuída a esta região.

\section{Considerações Finais}

A desertificação constitui um dos maiores problemas do planeta, acometendo milhares de pessoas no mundo inteiro. No entanto, os esforços empreendidos no que diz respeito ao combate à desertificação ainda são sobremaneira parcos, ao passo que os danos provocados pela mesma são excessivamente onerosos.

No Semiárido brasileiro, a desertificação já se faz presente em quase sua totalidade. Destarte, grande parte das terras do Semiárido estão comprometidas pela desertificação, destacando-se os níveis grave, muito grave e moderado. Não obstante, as terras do Semiárido brasileiro são muito susceptíveis ao fenômeno da desertificação, tendo em vista os fatores edafoclimáticos.

As mudanças climáticas e as secas no Semiárido contribuem fortemente para o agravamento e acentuação da desertificação nessa região, afora a predisposição geoecológica da região ao fenômeno em pauta. Para o IPCC, o Semiárido brasileiro pode se tornar uma região árida ao longo do tempo haja vista as mudanças climáticas associadas às secas. Destarte, as consequências disso poderão implicar em reduções da disponibilidade hídrica e no declínio das atividades agrícolas, 
comprometendo o fator socioeconômico e tornado a população que habita a região semiárida do Brasil mais vulnerável.

Conforme exposto no artigo, o Semiárido poderá sofrer grandes mudanças no setor agrícola devido à ausência de políticas públicas de combate e mitigação à desertificação e estratégias de enfrentamento às secas e às mudanças climáticas. Destarte, estas mudanças poderão desencadear o declínio do PIB do Brasil e, concomitantemente, do Semiárido brasileiro, com efeitos deletérios para a economia do país e da região em questão.

\section{REFERÊNCIAS}

AUBRÉVILLE, André. Climats, Forêts et Desertification de l'Afrique Tropicale. Paris: Société d'Editions Géographiques Maritimes et Coloniales,1949.

ANGELOTTI, F.; FERNANDES JÚNIOR, P. I.; SÁ, I. B. de. Mudanças Climáticas no Semiárido Brasileiro: Medidas de Mitigação e Adaptação. Revista Brasileira de Geografia Física, Recife, v. 06, p. 1097-1111, 2011.

ARENQUE, B. C. et al. Responses of Senna reticulata, a legume tree from the Amazonian flood plains to elevated atmospheric $\mathrm{CO}_{2}$ cencentration and water logging. Trees, v. 28, p. 1021-2034, 2014.

BOTELHO, C. L.Seca: Visão Dinâmica, Integrada e Correlações. Fortaleza: ABC, 2002.

CARVALHO, Otamar. As secas e seus impactos. In: A Questão de Água no Nordeste. Centro de Gestão e Estudos Estratégicos - CGEE, Agência Nacional das Águas - ANA. Brasília, 2012.

CERRI, C.C.; CERRI, PELLEGRINE, C.E. Agricultura e aquecimento global. Boletim Informativo da SBCS, v.23, p.40-44, 2007.

CONTI, J. B. Desertificação nos Trópicos: Propostas de Metodologia de Estudo Aplicada ao Nordeste Brasileiro. 1995. Tese de Livre Docência (Cento de Filosofia e Ciências humanas) - Universidade da São Paulo, USP, São Paulo.

D'ODORICO, P. el al. Global Desertification: Drivers and Feedbacks.Advances in Water Resources. Elsevier, n. 51, p. 326 - 344, 2013.

DECONTO, J. G. Aquecimento global e a nova geografia da produção agrícola no Brasil. Embrapa Informática Agropecuária - Unicamp, Campinas, 2008.

FÉRES, J., E. REIS e J. SPERANZA. Mudanças climáticas globais e seus impactos sobre os padrões de uso do solo no Brasil. In: XXXVII Encontro Nacional de Economia, Foz do Iguaçu, 2009. Disponível em: http://www.anpec.org.br/encontro 2009.ht. Acesso: 10 de julho de 2018.

Food and Agriculture Organization of the United Nations - FAO. Tracking adaptation in agricultural sectors: Climate change adaptation indicators. Rome, 2017. Disponível em: http://www.fao.org/3/a-i8145e.pdf. Acesso: 08 de julho de 2018.

HERRMANN, M.S.; HUTCHINSON, C. F. The Scientific Basis: Linkings between Land Degradation, Drought, and Desertification. In: JOHNSON, P. M.; MAYRAND, K.; PAQUIN, 
M. Governing Global Desertification: Linking Environmental Degradation, Poverty and Participation. Hampshire: Ashgate Publishing, 2006.

IPCC - Intergovernmental Panel On Climate Change. AR 4. Climate Change 2007: impacts, adaptation and vulnerability. Working Group II to the Fourth Assessment Report of the Intergovernmental Panel on Climate Change (IPCC), 2007.

- International Panel on Climate Change. Climate Change 2014: Mitigation of $\overline{\text { climate }}$ change. Working group III contribuition to the fifth asessment repport of the Intergovernmental Panel on Climate Change. United States of America, 2014. Disponível em: http://www.ipcc.ch/pdf/assessment-report/ar5/wg3/ipcc wg3 ar5 full.pdf. Acesso: 09 de julho de 2018.

LE HOUÉROU, H. N. Climate Change, Drought and Desertification. Journal of arid Environments. P. 133-185, France, 1996.

LISBOA, M. A. O problema das secas. In: Dnocs. Dnocs: pensamentos e diretrizes. Fortaleza: DNOCS, 1984.

MA - Millennium Ecosystem Assessment. Ecosystems and Human well-Being:

Desertification synthesis.Washington - DC: World resources Institute, 2005.

MACEDO, M. R. Uma Abordagem Temática e Especial de Áreas Passíveis à

Desertificação na Região do Seridó - RN/ PB. 2007. 129 f. Dissertação (Mestrado em Geodésicas e Tecnologias da Geoinformação) - Universidade Federal de Pernambuco Recife.

MARENGO, J. A. Mudanças climáticas globais e seus efeitos sobre a biodiversidade: caracterização do clima atual e definição das alterações climáticas para o território brasileiro ao longo do século XXI. Brasília: MMA, 2008.

, J. A. O futuro clima do Brasil. Revista USP, n. 103, p. 25-32, 2014.

MARTINS, E. S. R.; MAGALHÃES, A. R. A seca de $2012-2015$ no Nordeste e seus impactos. Parc. Estrat. Ed. Especial, Brasília, v. 20, n. 41, p. 107-128, 2015.

MARIN, A. M. P. et al. Núcleos de Desertificação no Semiárido Brasileiro: Ocorrência Natural ou Antrópica? Parc. Estrat., Brasília, v. 17, n. ${ }^{0}$ 34, p. 87-106, 2012.

MEDEIROS, G. L. D. de. Mapeamento dos Agentes de Degradação Ambiental do Seridó. In: Seminário Internacional. Sociedade e Territórios no Semiárido Brasileiro: Em busca da Sustentabilidade. Campina Grande - PB, 2002.

MENDES, B. V. Desertificação do Semiárido. In: Documento sobre Desertificação no Nordeste. Brasília: SEMA/ MMA/ SUDENE, 1986.

MÉREGA, J. L. El Problema de la Desertificación. In: Desertificación y Sociedad Civil. Argentina: Fundación Del Sur, 2003.

NIMER, E. Desertificação: Realidade ou Mito? Revista Brasileira de Geografia,V. 50, N. 1, 1988.

OBERMAIER, M. Velhos e Novos dilemas nos sertões: Mudanças Climáticas, Vulnerabilidade e Adaptação no Semiárido Brasileiro. 2011. 167 f. Tese (Doutorado em Planejamento Energético) - Universidade Federal do Rio de Janeiro, Rio de Janeiro, 2011. 
POMPEU SOBRINHO, T. História das Secas. Mossoró - RN, Coleção Mossoroense, v. CCXXVI, 1982.

RIBEIRO, M. R.; FREIRE, F. J.; MONTENEGRO, A. A. A. Solos halomórficos no Brasil:Ocorrência, gênese, classificação, uso e manejo sustentável. In: CURI, N.; MARQUES, J. J.; GUILHERME, L. R. G.; LIMA, J. M.; LOPES, A. S; ALVAREZ, V. H. (eds.). Tópicos em Ciência do Solo. Sociedade Brasileira de Ciência do Solo, Viçosa, v.3, p.165208, 2003.

ROXO, Maria José. Panorama Mundial da Desertificação. In: MOREIRA, Emília. (Org.), Agricultura Familiar e Desertificação. João Pessoa: EDUFPB, 2006, p. 11.

SAMPAIO, E. V. de S.B. et al. Desertificação no Brasil: Conceitos, Núcleos e Tecnologias de Recuperação e Convivência. Recife: Editora Universitária da UFPE, 2003.

SANTOS, P. P. dos. Evolução Econômica do Rio Grande do Norte: Clima. Natal, RN, 1994. In: Seminário sobre Desertificação no Nordeste. Documento Final. Brasília: SEMA/ SUDENE, 1986.

SILVA, G. G. A Problemática da Desertificação no Ecossistema da Caatinga do Município de São João do Cariri. 1993. 93 f. Monografia (Núcleo de Pesquisa e Controle da desertificação no Nordeste) - Universidade Federal do Piauí, Teresina.

STEINBECK, J. The Grapes of Wrath. New York: Pequin Books, 1996.

SZILAGYI, G. Diagnóstico Ambiental do Processo de Desertificação no Município de Lages/RN. 2007. 110 f. Dissertação (Mestrado em Estudos de Geografia) - Universidade Federal do Rio Grande do Norte, Natal.

TAVARES, V.C.; RAMOS, N.L. A desertificação em São João do Cariri /PB: uma análise das vulnerabilidades. Revista Brasileira de Geografia Física, Recife, v. 09, n. 05, p. 1384 1399, 2016.

TAIZ, L.; ZEIGER, E. Fisiologia Vegetal. Porto Alegre: Artemed, 5 Ed., 2013. VASCONCELOS SOBRINHO, João. A desertificação Brasileira. Brasília: Câmara dos Deputados, 1976.

WALTER, L. C.; ROSA, H. T.; STRECK, N. A. Mecanismos de aclimatação das plantas à elevada concentração de CO2. Revista Ciência Rural, Santa Maria, v.45, n.9, p.1564-1571, 2015.

\section{NOTAS DE AUTOR}

\section{CONTRIBUIÇÃO DE AUTORIA}

Válter Cardoso Tavares - Concepção e elaboração do manuscrito; Coleta de dados, Análise dos dados, Revisão e aprovação final do artigo.

Ítalo Rodrigo Paulino de Arruda - Análise dos dados, Revisão e a aprovação final do artigo.

Danielle Gomes da Silva - Participação ativa da discussão dos resultados, Revisão e aprovação final do artigo.

FINANCIAMENTO

Não se aplica.

CONSENTIMENTO DE USO DE IMAGEM

Não se aplica.

APROVAÇÃO DE COMITÊ DE ÉTICA EM PESQUISA 
Não se aplica.

CONFLITO DE INTERESSES

Não se aplica.

\section{LICENÇA DE USO}

Este artigo está licenciado sob a Licença Creative Commons CC-BY. Com essa licença você pode compartilhar, adaptar, criar para qualquer fim, desde que atribua a autoria da obra.

\section{HISTÓRICO}

Recebido em: 19-04-2018

Aprovado em: 03-08-2018 